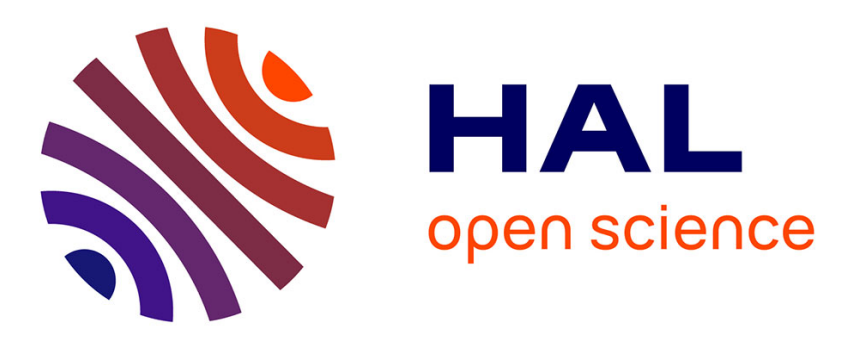

\title{
Identification of sensitive R-L parameters of a Multi-phase drive by a vector control
}

Antoine Bruyère, Eric Semail, Fabrice Locment, Alain Bouscayrol, J.M Dubus, Jean-Claude Mipo

\section{To cite this version:}

Antoine Bruyère, Eric Semail, Fabrice Locment, Alain Bouscayrol, J.M Dubus, et al.. Identification of sensitive R-L parameters of a Multi-phase drive by a vector control. IEEE Power Electronics Specialists Conference, Jun 2008, Rhodes, Greece. pp.1-5. hal-01107782

\section{HAL Id: hal-01107782 \\ https://hal.science/hal-01107782}

Submitted on 3 Feb 2015

HAL is a multi-disciplinary open access archive for the deposit and dissemination of scientific research documents, whether they are published or not. The documents may come from teaching and research institutions in France or abroad, or from public or private research centers.
L'archive ouverte pluridisciplinaire HAL, est destinée au dépôt et à la diffusion de documents scientifiques de niveau recherche, publiés ou non, émanant des établissements d'enseignement et de recherche français ou étrangers, des laboratoires publics ou privés. 


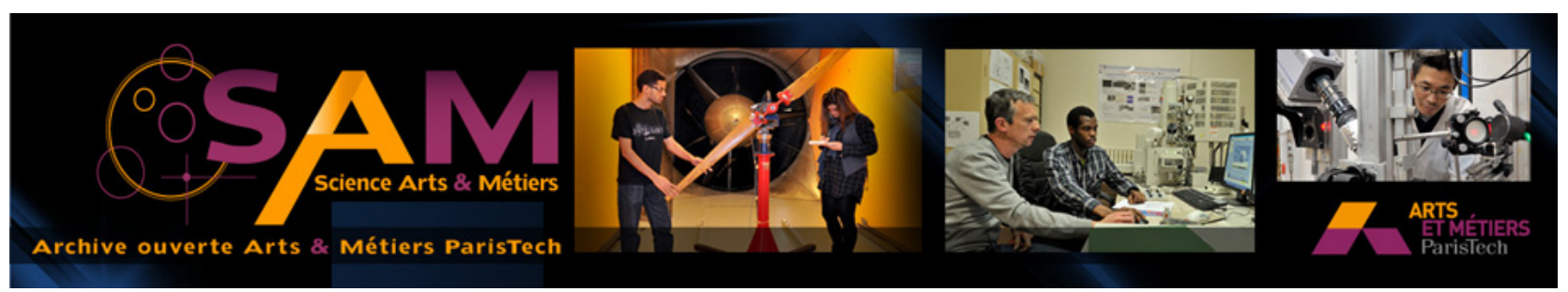

\section{Science Arts \& Métiers (SAM)}

is an open access repository that collects the work of Arts et Métiers ParisTech researchers and makes it freely available over the web where possible.

This is an author-deposited version published in: http://sam.ensam.eu

Handle ID: .http://hdl.handle.net/10985/9256

\section{To cite this version :}

Antoine BRUYĖRE, Eric SEMAIL, Alain BOUSCAYROL, Jean-Marc DUBUS, Jean-Claude MIPO - Identification of sensitive R-L parameters of a Multi-phase drive by a vector control - In: IEEE Power Electronics Specialists Conference, Greece, 2008-06 - Power Electronics Specialists Conference - 2008 


\title{
Identification of sensitive R-L parameters of a multiphase drive by a vector control
}

\author{
A. Bruyere ${ }^{*, * *}$, E. Semail ${ }^{*}$, F. Locment ${ }^{*}$, A. Bouscayrol ${ }^{*}$, J.M. Dubus ${ }^{* *}$, J.C. Mipo ${ }^{* *}$ \\ * Arts et Métiers ParisTech, L2EP, Lille, FRANCE \\ ${ }^{* *}$ Valeo Electrical System, Créteil, FRANCE
}

\begin{abstract}
This paper focuses on an experimental method to determine the electric parameters of a seven-phase lowvoltage multiphase drive. The drive is a belt driven starteralternator for powerful cars with Hybrid Electrical Vehicles (HEV) functions. The resistive and inductive parameters are necessary to obtain the six characteristic time constants of the control modeling. Classical direct measurements lead to imprecise results because of very low values for the windings electric resistance (a few $\mathrm{m} \Omega$ ) and inductance (a few $\mu \mathrm{H})$. Effects of the imprecision on the measurements are all the more important that time constants are obtained by a ratio of cyclic inductances by resistance, with cyclic inductances being a linear combination of seven measured inductances. The methodology for identification detailed in this paper is based on a stator current vector control, in a multi-reference frame. This methodology allows us to get directly these time constants. Numerous measurements allow the robustness of the method to be evaluated.
\end{abstract}

\section{INTRODUCTION}

Reducing petrol consumption and $\mathrm{CO} 2$ emission is now assumed to be one of the great new societal and economical issues. In this context, automotive suppliers as Valeo, offer new solutions to make cars less costly in terms of energy and less polluting. One of these solutions consists in adding electrical machines running with the classical Internal Combustion Engine (ICE) to make it work more efficiently; it is the principle of Hybrid Electric Vehicles (HEV) [1]-[2]-[3]. From a small ten years, several hybrid cars structures have appeared on the market. This paper deals with the cheaper one: the starteralternator system [4]-[5]-[6]. This system is composed of a classical car generator, i.e. a claw pole synchronous machine, but with a Voltage Source Inverter (VSI) instead of the diode bridge; the claw-pole machine can then be used as motor. Starter-alternators already equip small cars, with a small ICE, as the Citroën $\mathrm{C} 3$, and are used to a unique function: the Stop-start function [5]-[6]. The major interest of this simple system concerns the limited extra cost for the final car. In order to extend the range of models equipped with a start-alternator or to extend the system capabilities, there is a need to increase its power. Previous works [7] show the interest of multiphase (with more than 3 phases) VSIs to improve the use of the DCbus voltage. Moreover, the use of multiphase machines also enables the increase of torque density by using new windings [8]. It is thus possible to extend the power range,

This work was supported by the French car supplier Valeo and the regional council of France Region-Nord-Pas-De-Calais. keeping the standard low cost low voltage level of $14 \mathrm{~V}$.

With the final objective to explore the capabilities of this kind of system, this paper focuses on the first difficulty: the determination of the control modeling parameters such as resistance, inductances and time constants. In a seven-phase machine with usual voltages, the determination of these parameters is already sensitive [9]. With the studied machine, this sensitivity is amplified because of the low values of resistance (a few $\mathrm{m} \Omega$ ) and inductances (a few $\mu \mathrm{H})$ induced by the low voltage value of the DC-bus. The original methodology of identification presented in this paper lies on a vector control of the multiphase machine currents, in a multi-reference dq frame based on a generalized Concordia transformation [10]-[11]. In the first part of this paper, the 7-phase drive modeling in the multi-reference frames is introduced. In the second part, the methodology of identification is presented. In the last part, experimental results are discussed.

\section{MODELING THE 7-PHASE DRIVE IN A CONTROL FRAME}

\section{A. Presentation of the 7-phase drive}

The drive: it is composed of a 7-phase wye-coupled claw-pole synchronous machine with separate excitation. The machine is supplied with a Voltage Source Inverter (VSI). MOSFETS transistors (MOS) are used for the VSI switches. In normal operating modes (with high currents level), voltage drops of MOS are supposed to be a linear function of the current. The DC-bus voltage $V_{D C}$ is imposed by a $12 \mathrm{~V}$ battery.

The experimental set-up: an experimental set-up has been developed in order to test control algorithms. It is described in Fig. 2. In this, the starter-alternator is directly mechanically connected to a brushless machine, used to simulate the ICE behavior. An electronic voltage source and an electronic load are used to replace the $12 \mathrm{~V}$ battery. The whole system is managed using a dSPACE ${ }^{\mathrm{TM}}$ DS1006 control board.

\section{B. Classical modeling of the 7-phase synchronous machine in the stator frame}

In the stator frame, the 7-phase synchronous machine is commonly modeled with the set of equations (1) and (2). In Fig.2, a classical scheme is used to introduce the common notations: $v_{k}$, as the phase " $k$ " voltage, and $i_{k}$ this phase current. The position of the rotor is $\theta$ and the 
excitation field current is $i_{F}$. In (1) and (2), $R_{S}$ is the phase resistance value, $\phi_{k}$, the magnetic flux linked by the phase $k$. The matrix $\left[\boldsymbol{L}_{S S}(\theta)\right]$ is the stator inductance matrix, whose terms depend on the position $\theta . M_{S R} f(\theta)$ is a Stator/Rotor linkage function.

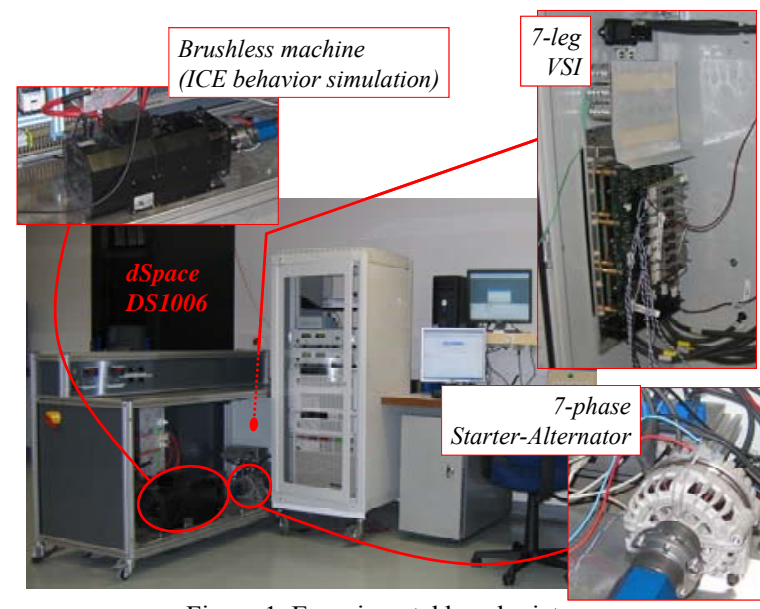

Figure 1. Experimental bench picture

In the stator frame, electrical parameters to be determined are then: the stator resistance $R_{S}$, the electromotive forces and the terms of the matrix $\left[\boldsymbol{L}_{S S}(\theta)\right]$. In this paper, we focus on $R_{S}$ and $\left[\boldsymbol{L}_{S S}(\theta)\right]$ :

$R_{S}$ measurement in the stator frame: this measurement is quite difficult in the stator frame, because of its very low value (a few $\mathrm{m} \Omega$ ). Indeed, at first, to get a sufficient precision on the measurement, it is necessary to supply the windings with a sufficient voltage values. This implies very high value of current to flow through the windings (several hundreds of amperes). Moreover, the windings resistance value is close to the parasitic resistances (connection and wires resistances, MOS resistance ...). So, it is necessary to use a methodology which takes into account all these parasitic resistances.

Terms of $\left[\mathbf{L}_{S S}(\theta)\right]$ measurement in the stator frame: This measurement is the most difficult, firstly, because of the very low value of the inductive terms, secondly, because of the evolution of the matrix terms. Indeed, $\left[\boldsymbol{L}_{S S}(\theta)\right]$ is a full matrix, whose each term varies with the position $(\theta)$ and the magnetic state, which depends on the currents $\left(i_{F}\right.$ and $\left.i_{S}\right)$ values. So, it is difficult to determine the variation laws of the 49 inductive terms.

Finally, in order to control the machine, the needed parameters are time constants, i.e. ratios between inductive parameters and resistance. Then, a low precision on measurement of both inductances and resistances can lead to a completely false estimation of these time constants. In the second part, an original methodology is presented, which allows a direct estimation of these time constants.

$$
\begin{aligned}
& {[v]^{T}=R_{S}[i]^{T}+\frac{d[\phi]^{T}}{d t}} \\
& {[v]^{T}=R_{S}[i]^{T}+\frac{d[\phi]^{T}}{d t}=\left[\mathrm{L}_{\mathrm{SS}}(\theta)\right][i]^{T}+M_{S R}[f]^{T} i}
\end{aligned}
$$

$$
\begin{aligned}
{[v] } & =\left[\begin{array}{lllllll}
v_{1} & v_{2} & v_{3} & v_{4} & v_{5} & v_{6} & v_{7}
\end{array}\right] ; \\
{[i] } & =\left[\begin{array}{llllllll}
i_{1} & i_{2} & i_{3} & i_{4} & i_{5} & i_{6} & i_{7}
\end{array}\right] ; \\
{[\varphi} & =\left[\begin{array}{lllllll}
\varphi_{1} & \varphi_{2} & \varphi_{3} & \varphi_{4} & \varphi_{5} & \varphi_{6} & \varphi_{7}
\end{array}\right] ; \\
{[f] } & =\left[\begin{array}{lllllll}
f_{1} & f_{2} & f_{3} & f_{4} & f_{5} & f_{6} & f_{7}
\end{array}\right] ; \\
f_{k} & =f(\theta-2(k-1) \pi / 7)
\end{aligned}
$$

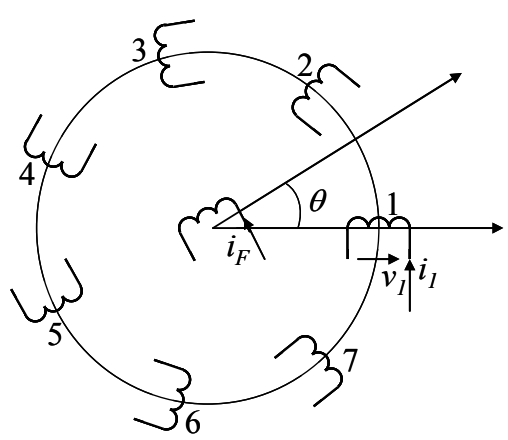

Figure 2. Schematic representation of the 7-phase synchronous machine with separate excitation

\section{Modeling in a control frame}

The methodology of the electrical parameters identification presented in this paper lies on a control of currents in the generalized Concordia frame [10]-[11]. This is particularly interesting because the dynamic control of the alternative machines is generally established once the problem (1)-(2) has been transposed in this frame. Then, studying the special case of a 7-phase machine, the mathematical transformation leads to a projection of the problem in 3 orthogonal dq-subspaces, named "S1-subspace", "S2-subspace" and "S3-subspace" (or S1, S2 and S3) [10]-[11]. This transformation yields a decoupled set of voltage equations, expressed with (3) in the S1, S2 and S3 subspaces. The first equation is related to the 0 -sequence component, in a 0 -sequence subspace, which is ignored because the electrical wye-coupling of the machine implies an always null $i_{0}$ current. Then, the 6 other equations yields a very classical and simple scheme (Fig. 3.) for controlling each dq-current expressed, in the 3 subspaces $\mathrm{S} 1, \mathrm{~S} 2$ and $\mathrm{S} 3$. In these equations, the $L_{S}$ terms are the cyclic inductances. As an example, $L_{S I-d}$ is the cyclic inductance related to the d-axis in the S1-subspace. These cyclic inductances are a linear combination of seven elements of $\left[\mathrm{L}_{\mathrm{SS}}(\theta)\right]$. As consequence, if these cyclic inductances are determined directly from elements of $\left[\boldsymbol{L}_{S S}(\theta)\right]$, there is an accumulation of uncertainties.

$$
\left\{\begin{array}{l}
v_{0}=L_{0} d\left(i_{0}\right) / d t+R_{S} i_{0}+e_{0} \\
v_{S 1-d}=L_{S 1-d} d\left(i_{S 1-d}\right) / d t+R_{S} i_{S 1-d}+e_{S 1-d} \\
v_{S 1-q}=L_{S 1-q} d\left(i_{S 1-q}\right) / d t+R_{S} i_{S 1-q}+e_{S 1-q} \\
v_{S 2-d}=L_{S 2-d} d\left(i_{S 2-d}\right) / d t+R_{S} i_{S 2-d}+e_{S 2-d} \\
v_{S 2-q}=L_{S 2-q} d\left(i_{S 2-q}\right) / d t+R_{S} i_{S 2-q}+e_{S 2-q} \\
v_{S 3-d}=L_{S 3-d} d\left(i_{S 3-d}\right) / d t+R_{S} i_{S 3-d}+e_{S 3-d} \\
v_{S 3-q}=L_{S 3-q} d\left(i_{S 3-q}\right) / d t+R_{S} i_{S 3-q}+e_{S 3-q}
\end{array}\right.
$$

with 


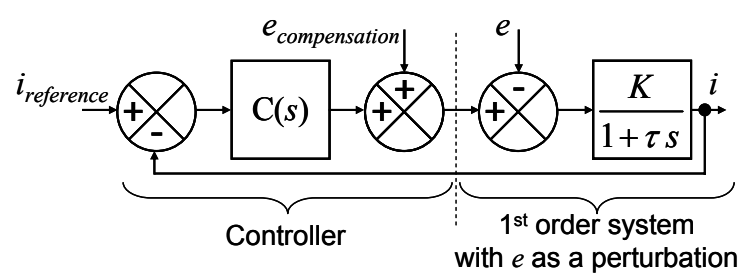

Figure 3. Control of one single axis of a dq subspace

\section{IDENTIFICATION OF THE ELECTRICAL PARAMETERS IN CONTROL SUBSPACES}

In the first section, two ways of modeling the 7-phase synchronous machine have been introduced: in the stator frame (1)-(2) and in the generalized Concordia frame (3). The second one is generally used for a dynamic control of the machine (torque or speed control). The common methodologies for identifying the electrical parameters generally consist in the measurement of these parameters in the stator frame, i.e. in a frame where voltages and currents are directly measurable, and then to make the projection of these parameters in the Concordia frame. Here, the methodology consists in directly measuring the parameters in the generalized Concordia frame.

These parameters are determined while controlling the six independent currents on both d- and q-axes, in S1, S2 and S3. Fig.3 gives the model and the scheme for controlling only one of these currents: the parameters to be determined are $K$ (the static gain, with $K=1 / R_{S}$ ) and $\tau$ (the time constant of the first order system, with $\tau=L_{S}$ $\left./ R_{S}\right)$. " $e$ " is the electromotive force, considered to be a perturbation in the model is compensated in the control by a feedforward action. Finally, $\mathrm{C}(s)$ represents the controller.

In the dq-spaces (3), the currents are then constant values in steady-state operation. The Matlab ${ }^{\mathrm{TM}}$ Simulink $^{\mathrm{TM}}$ scheme used to control the whole system is given on Fig. 4 and is directly implemented in the dSPACE ${ }^{\mathrm{TM}}$ real time control board system. In this figure, it appears: (a), the step form references which can be imposed to each dqcurrent in the three different dq-subspaces, (b), the measurement of the "real" (in the stator frame) seven phase currents and their projection in the dq-subspaces, (c), the control structure of each current, (d), the estimation of the electromotive forces, in order to make the compensation and to minimize the perturbations on the different dq-axis , (e), the "inverse" transformation from the three dq-subspaces to the stator frame, and (f) the "real" system on which the control orders of the VSI are transmitted.

In order to identify time constant and gain relative to one of the six d-q axes, the approach is the following:

a) Firstly, constant references of current are chosen in the five other axes and PI controllers are tuned in order to minimize interaction between the axes;

b) secondly a proportional controller is chosen for the studied axis with a step waveform reference for the current;

c) finally, measurements of closed loop static error and closed loop time constant allows us, according to Fig3., to determine open-loop $K$ gain and $\tau$ time constant.

Fig. 5 gives an example of the dq-currents waveforms in $\mathrm{S} 1, \mathrm{~S} 2$ and $\mathrm{S} 3$-subspaces, obtained when the square wave reference is imposed to the q-axis in S1. So, this test aims at determining $R_{S}$ and $L_{S l-q}$. For this example, the average working point is specified as followed: $I_{F}=3 \mathrm{~A}$ and $\left\langle\mathrm{i}_{S 1-q}\right\rangle=-200 \mathrm{~A}$. The square wave reference, with a 20A (Fig.5-(S1)) magnitude, is imposed around the average working point. The measured current along the qaxis in $\mathrm{S} 1$ is shown in Fig. 5. Its waveform corresponds to a first order system response, which allows the use of the model described in Fig. 3. All other currents are null. In this example, the proportional gain used for controlling $i_{\mathrm{S} 1-}$ ${ }_{\mathrm{q}}$ is $\mathrm{K}_{\mathrm{p}-\mathrm{S} 1-\mathrm{q}}=0.02$. The measured static gain is $9.4 / 20=$ 0.47 . The deduced value of the stator resistance is $R_{s}=$ $22.6 \mathrm{~m} \Omega$. The direct measurement of the closed loop time constant is $\tau_{\mathrm{S} 1 \text {-q-closed-loop }}=1.14 \mathrm{~ms}$. This implies a value for the open loop time constant $\tau_{\mathrm{S} 1-\mathrm{q}}=2.15 \mathrm{~ms}$ and for the inductance $L_{\mathrm{S} 1-\mathrm{q}}=\tau_{\mathrm{S} 1-\mathrm{q}} R_{S}=48.5 \mu \mathrm{H}$.

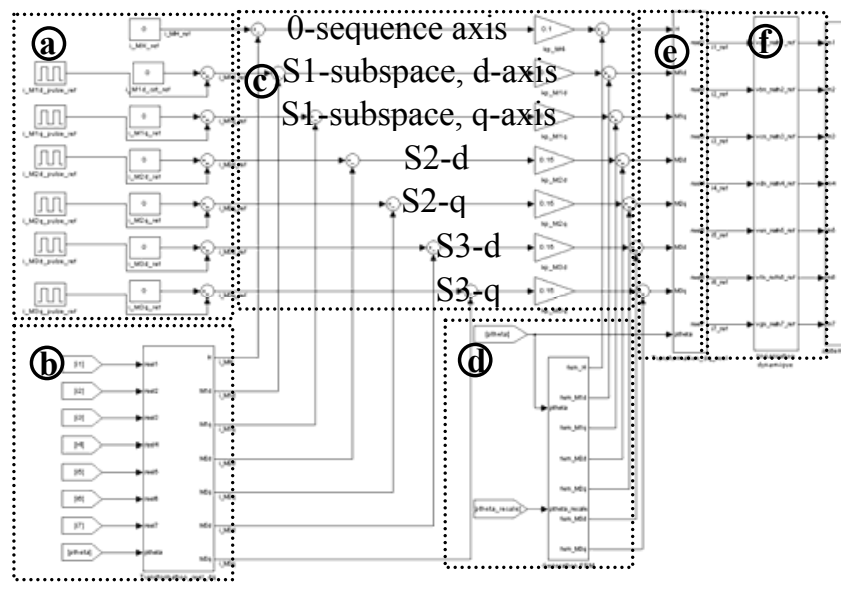

Figure 4. 7-phase synchronous machine control structure; Matlab ${ }^{\mathrm{TM}}$ Simulink ${ }^{\mathrm{TM}}$ representation for $\mathrm{dSPACE}^{\mathrm{TM}}$ implementation

\section{GLOBAL EXPERIMENTAL RESULTS}

In this part, robustness of the method is firstly examined on one axis. Secondly, the uncertainty on the stator resistance is evaluated by using the results obtained on the six d-q axes. Finally, evolution of the six time constants with the excitation current is given. The rotation speed is always null and the square wave reference magnitude is always 20A, around an average current on the studied axis of 200A.

\section{A. Repititiveness of the measurement}

As a first test, we want to examine the repetitiveness of the measures. Fig. 6 shows the evolution of the resistance (measured along the q-axis in S1, Fig. 6-(a)) and of the dand q-time constants in S1 (Fig. 6-(b)). For each measurement, two curves have been plotted: "meas 1 " and "meas2", in exactly the same conditions. Moreover, for this test, the proportional gain used for the controller on the studied axes (S1-q axis for Fig.6-(a); S1-d and S1-q axes for Fig.6-(b)) is the same gain as in the test described in Fig.5, i.e. $K_{p}=0.02$. These measurements have been done for different excitation currents.

Finally, as the described identification is supposed to be independent of $\mathrm{K}_{\mathrm{p}}$, tests have been done for different values of $\mathrm{K}_{\mathrm{p}}$. So, for two excitation currents, $i_{F}=3 \mathrm{~A}$ and $i_{F}=7.5 \mathrm{~A}$, the measurement has been made for: $\mathrm{K}_{\mathrm{p}}=0.01$, $\mathrm{K}_{\mathrm{p}}=0.02$ and $\mathrm{K}_{\mathrm{p}}=0.04$. For each case, two measurements have been made. This means that for these two excitation values, six measurements are compared 
(circled zones). The measurements show a small variation of the results with the value of $K_{p}$.

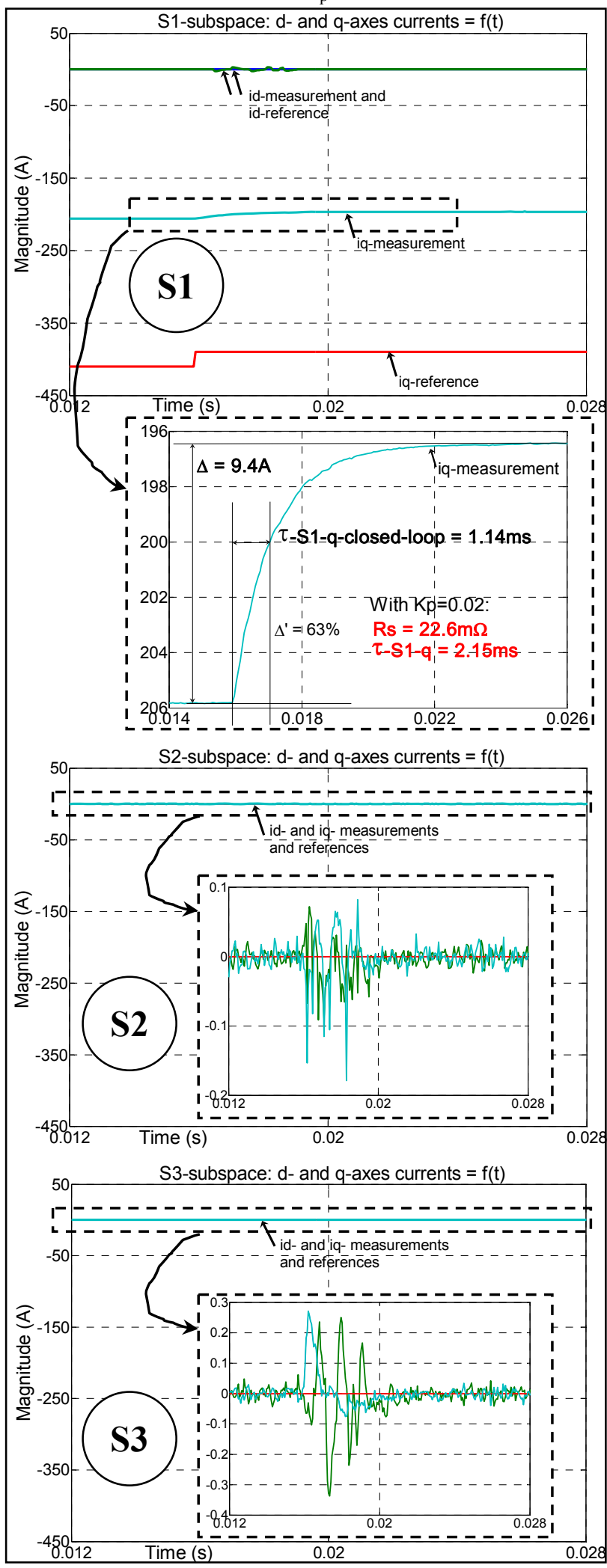

Figure 5. Example of experimental results for a specific operating point: $N=0 \mathrm{rpm}, i_{F}=3 \mathrm{~A}$; Step reference is imposed to the q-axis in S1subspace and null references in the other axes
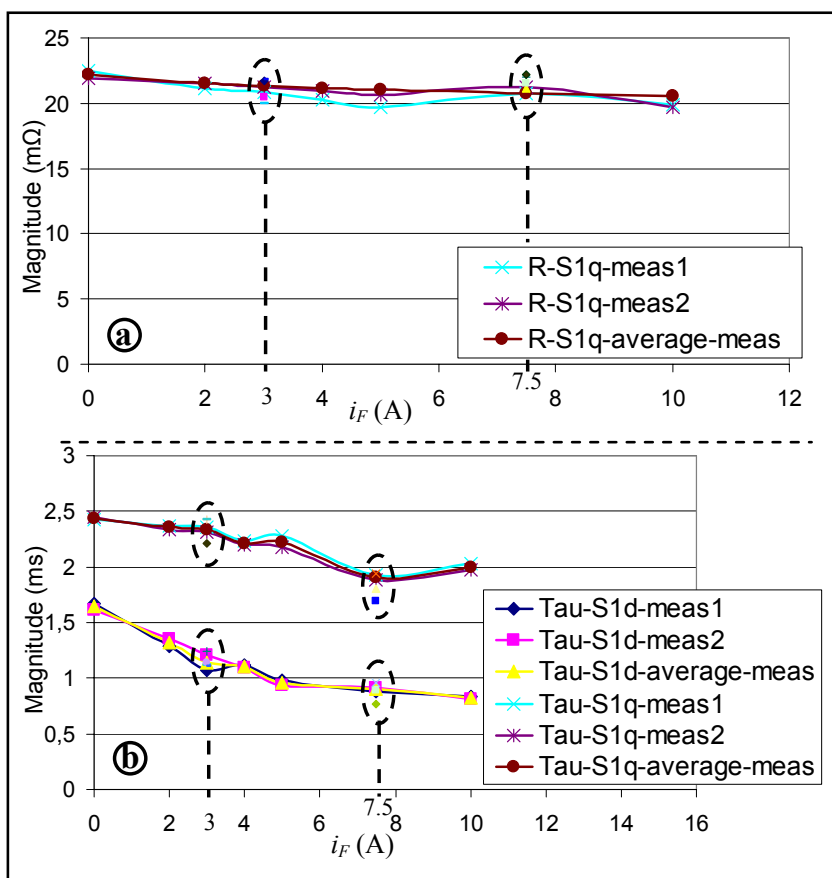

Figure 6. Evolution of the resistance in S1-d (a) and the time constants in S1 (b) as functions of the excitation current; and comparison of different values of $\mathrm{K}_{\mathrm{p}}$ (circled zones)

\section{B. Measurement of the resistance}

According to the model in the generalized Concordia frame (3), there is just one defined resistance $R_{S}$. Indeed, the seven phases are supposed to be identical (from the electrical point of view). There are 6 ways to measure $R_{S}$ (two measurements on each d- or q-axis, in three subspaces S1, S2 or S3). The same value of resistance is supposed to be found for each measurement, in $\mathrm{S} 1-\mathrm{d} / \mathrm{q}$, $\mathrm{S} 2-\mathrm{d} / \mathrm{q}$ and $\mathrm{S} 3-\mathrm{d} / \mathrm{q}$. It must be remarked that the measured resistance takes into account the equivalent resistance of MOSFET transistor of the VSI and all the parasitic resistances of wires and connections. Fig. 7 shows the evolution of the resistance as a function of the excitation current $i_{F}$ : the resistance appears to be quite constant while $i_{F}$ is changing. The global mean value is $R_{S}=$ $21.74 \mathrm{~m} \Omega$. Table 1 gives the "partial" (related to each axis) mean values of the resistance, for each measurement. It also gives the relative error (in \%) of these partial mean values relating to the average value. The maximal error, $10.7 \%$, is given for the measurement on S3-q axis. A model using a single constant resistance $R_{S}$ appears then correct.

\begin{tabular}{|l|c|c|c|c|c|c|}
\hline Axis: & S1-d & S1-q & S2-d & S2-q & S3-d & S3-q \\
\hline $\begin{array}{l}\text { Mean resistance } \\
\text { value (m) : }\end{array}$ & 20.3 & 21.2 & 21.3 & 21.9 & 21.7 & 24.1 \\
\hline $\begin{array}{l}\text { Relative error } \\
\text { relating to the } \\
\text { average value (\%): }\end{array}$ & -6.7 & -2.3 & -2.2 & 0.57 & -0.11 & 10.7 \\
\hline
\end{tabular}

Table 1. Mean measured resistance value in $\mathrm{S} 1 / 2 / 3-\mathrm{d} / \mathrm{q}$ and relative error relating to the average value $\left(R_{S}=21.7 \mathrm{~m} \Omega\right)$ 


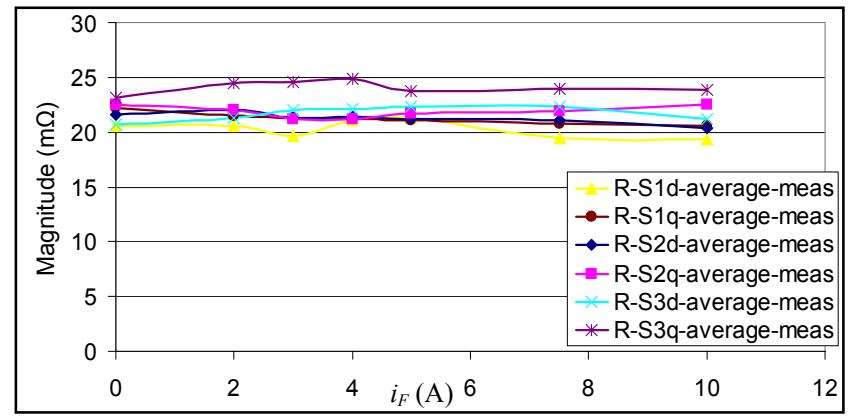

Figure 7. Evolution of the measured resistance in S1, S2 and S3, as a function of the excitation current

\section{Measurement of the time constants}

Fig. 8 gives the evolution of the time constants measured in the three subspaces S1, S2, S3 (on d- and qaxes), as a function of $i_{F}$. These time constants (and so, the inductances) decrease while the excitation current increases. This is due to the evolution of the magnetic materials properties, which proves their non-linear characteristic. This magnetic state depends on the currents (phase currents and excitation current). Here, the characteristic is just given as a function of the excitation current at a specific operating point. The evolution of the time constant with the stator currents evolution is not given. Nevertheless, the same approach has been lead at other operating points, and at different rotation speeds. The same measurements can be established as described in this paper without any major difficulty. The presented results, at a null rotation speed, correspond to the easiest measurement, because of a good decoupling between the six axes.

Finally, another point must be observed with the results shown at this operating point, particularly in S1: the inductance on the d-axis is much different with the inductance on the q-axis. This is due to variable reluctance effects. For this machine, at this operating point, the reluctant effects affect mainly the $\mathrm{S} 1$ subspace. For the other S2 and S3 subspaces, the $\mathrm{d}-$ and $\mathrm{q}$ - inductive parameters are almost the same.

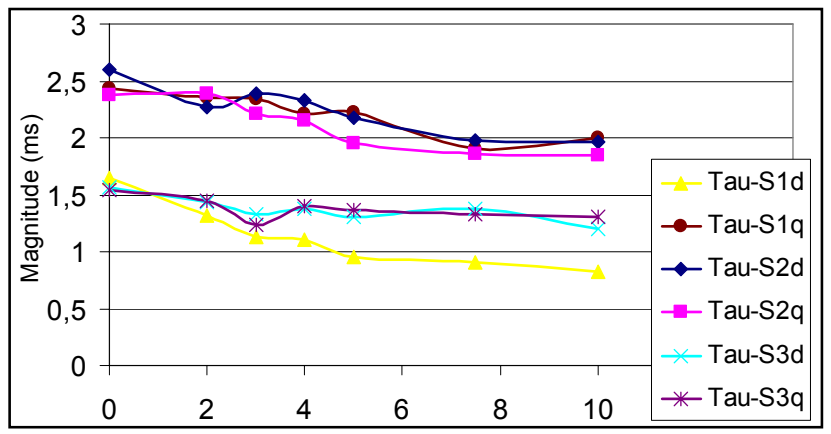

Figure 8. Evolution of the time constants measured in S1, S2 and S3, as a function of the excitation current

\section{CONCLUSION}

In order to establish the control of a 7-phase starter alternator drive and to build virtual models, a good knowledge of its electrical parameters and time constants is needed. Due to the low voltage and the high number of phases of the studied drive, indirect determination of the time constants, using classical inductive measurements in the stator frame, implies uncertainties.

In this paper, an experimental methodology for identifying directly in the Concordia frame, in which are determined the cyclic inductances, has been presented. Numerous measurements have been carried out to prove its robustness. Moreover, this methodology allows us to take into account all parasitic resistances (of the MOSFET transistors and at electrical connections), which are not negligible in this low voltage automotive application: it is really the identification of the drive and not of the electrical machine that has been achieved.

The results have been given for a specific operating point, at null rotation speed. Nevertheless, the developed methodology has been also used at other operating points. Concerning more specifically the studied drive, the variations of the time constants with the excitation currents have been given, with a noticeable difference between the three characteristic subspaces S1, S2 and S3: only $\mathrm{S} 1$ subspace presents two different $L_{d}$ and $L_{q}$ cyclic inductances.

\section{REFERENCES}

[1] V. Wouk, "Hybrids: then and now", IEEE Spectrum, Vol. 2, Issue 7, pp. 16-21, ISSN : 0018-9235, July 1995.

[2] A. Emadi, M. Ehsani, J. M. Miller, "Vehicular Electric Power Systems", Marcel Dekker, 2004, ISBN 0-8247-4751-8.

[3] M. Ehsani, Y. Gao, S. E. Gay, A. Emadi, "Modern Electric, Hybrid Electric, and Fuel Cell Vehicles", CRC PRESS, 2005, ISBN 0-8493-3154-4.

[4] W. Cai, "Comparison and review of electric machines for integrated starter alternator applications", Industry Applications Conference. 39th IAS Annual meeting. Conference Record of the 2004 IEEE, Vol. 1, 3-7 Oct. 2004, pp. - 393.

[5] D. Richard, Y. Dubel, "Valeo StARS Technology: A competitive Solution for Hybridization", Power Conversion Conference, PCC '07, Nagoya, Japan, pp. 1601-1605, April 2007, ISBN: 1-42440844-X.

[6] K. Cogo, J.M. Dubus, C. Plasse, "The Valeo belt driven starter alternator reversible systems", congrès alternatives énergétiques dans l'Automobile, Poitiers, France, n772, pp. 44-49, April 2004.

[7] F. Locment, A. Bruyere, E. Semail, X. Kestelyn, A. Bouscayrol and J. M. Dubus, "Comparison of 3-, 5- and 7-leg Voltage Source Inverters for low voltage applications", IEEE International Electric Machines and Drives Conference, IEMDC 2007, Antalya, Turkey, pp. 1234-1239, May 2007, ISBN: 1-4244-0743-5.

[8] J. M. Dubus, A. De Vries, D. Even and J. C. Mipo: "Polyphase stator of a rotating electrical machine with claw-pole rotor and alternator or alternator starter comprising same", French Patent WO 2007/031679 A2, March 2007.

[9] F. Locment, E. Semail, F. Piriou, « Design and Study of a Multiphase Axial-flux machine ", IEEE Transactions on Magnetics, Vol. n42, n4, april 2006, pp. 1427-1430.

[10] J. Figueroa, J. Cros, P. Viarouge, "Generalized transformations for polyphase phase-Modulation motors", IEEE Transaction on Energy Conversion, Vol. 21, Issue 2, pp. 332-341, June 2006, ISSN: 0885-8969.

[11] E. Levi, R. Bojoi, F. Profumo, H. A. Toliyat, S. Williamson, "Multiphase induction motor drives- A technology status review", Electric Power Applications, IET, Vol. 1, issue 4, pp. 489-516, July 2007. 